\title{
Comparison of oral versus intra-articular tranexamic acid in enhanced-recovery primary total knee arthroplasty without tourniquet application: a randomized controlled trial
}

Duan Wang ${ }^{1+}$, Hui Zhu ${ }^{2,3+}$, Wei-Kun Meng ${ }^{1+}$, Hao-Yang Wang ${ }^{1 \dagger}$, Ze-Yu Luo ${ }^{1}$, Fu-Xing Pei ${ }^{1}$, Qi Li ${ }^{i^{*}}$ and Zong-Ke Zhou ${ }^{1 *}$ (D)

\begin{abstract}
Background: Although randomized controlled trials have confirmed oral tranexamic acid (TXA) can provide similar blood-sparing efficacy compared with intravenous (IV) TXA in total knee arthroplasty (TKA), some concerns do remain about thromboembolic events after such systemic administration. Many studies have confirmed that intra-articular (IA) application of TXA can show similar blood-saving efficacy with minimal levels of systemic absorption compared with IV TXA. However, it remains unclear whether the efficacy and safety of oral TXA administration is equal to or less than that of IA administration in TKA without the use of a tourniquet and drain. Thus, this study was to verify non-inferior efficacy and safety of oral TXA compared with IA TXA in primary TKA.
\end{abstract}

Methods: A double-blind, randomized, controlled trial was performed to compare three oral doses of TXA ( $2 \mathrm{~g}$ of TXA $2 \mathrm{~h}$ before incision, and $1 \mathrm{~g}$ of TXA 6 and $12 \mathrm{~h}$ after surgery, respectively) with IA TXA (3 g of TXA in $100 \mathrm{~mL}$ of saline solution). One hundred forty-seven patients scheduled for TKA were randomized to one of the two interventions. The primary outcome was total blood loss. The secondary outcomes included reduction of hemoglobin concentration, clinical outcomes, blood coagulation values, thromboembolic complications, and transfusion rates.

Results: The mean total blood loss was $788.8 \mathrm{~mL}$ in the oral TXA group compared with $872.4 \mathrm{~mL}$ in the IA TXA group, with no statistical significance $(p>0.05)$. There were no significant differences in reduction of hemoglobin level, blood coagulation level, and clinical outcomes. The transfusion rates were $4 \%$ in oral group and 5\% IA group, respectively. Also, no significant differences were identified in thromboembolic complications.

Conclusion: Oral TXA according to the described protocol demonstrated non-inferiority for primary TKA, with no safety concerns and a greatly reduced cost, compared with the IA TXA. This randomized controlled trial supports the oral administration of TXA in TKA.

Trial registration: The trial was registered in the Chinese Clinical Trial Registry (ChiCTR-INR-17010968) dated 23rd March 2017.

Keywords: Total knee arthroplasty, Tranexamic acid, Oral, Intra-articular, Blood loss

\footnotetext{
*Correspondence: liqimm@yahoo.com; zongkehx@163.com

†'Equal contributors

'Department of Orthopedics, West China Hospital/West China School of

Medicine, Sichuan University, 37\# Wuhou Guoxue road, Chengdu 610041,

People's Republic of China

Full list of author information is available at the end of the article
} 


\section{Background}

Total knee arthroplasty (TKA) is viewed as one of the most successful orthopedic surgeries that relieves pain and improves function but is associated with excessive perioperative blood loss that might lead to anemia and blood transfusions [1-4]. Allogeneic transfusion may result in several undesirable adverse events, but not limited to, including infection, heart failure, immunologic reaction, and myocardial infarction, and as a consequence involve increased morbidity and mortality and additional health care costs [5-7]. Based on a multimodal fast-track methodology at many institutions, numerous blood-saving strategies have been suggested to successfully reduce surgery-related blood loss and minimize the risk of post-operative transfusions, such as perioperative blood salvage, autologous blood transfusion, intraoperative hypotensive anesthesia, application of cryotherapy, and use of pharmacologic antifibrinolytics such as tranexamic acid (TXA) [8-11].

Tranexamic acid, an antifibrynolitic medication, can prevent plasminogen activation by blocking the lysine binding site of plasminogen and inhibiting the formation of plasmin, and thereby promote coagulation process $[12,13]$. TXA can be administered either intravenously (IV), intra-articularly (IA), or orally in the setting of TKA. Oral administration of TXA had beneficial bloodand cost-saving effect, as confirmed in some randomized controlled trials (RCT), and also reduced transfusions without increased risk of thromboembolic complications compared with placebo [14, 15]. Compared with oral or IV TXA, the IA TXA can provide a maximum concentration of TXA in surgical site and thereby a prolonged effect to reduce postoperative blood loss, but is associated with minimal levels of systemic absorption, which may increase safety. Numerous RCTs [16, 17] and meta-analyses [18] showed valid evidence favoring the effectiveness of various dosages and routes of IA TXA in reducing blood loss and allogeneic transfusion requirements in TKA.

Recent RCTs and meta-analyses have confirmed that oral TXA showed similar blood-sparing efficacy, at a greatly reduced cost, compared with IV TXA $[19,20]$. In spite of the potential cost-saving benefits of oral TXA, some concerns do remain about thromboembolic events after systemic administration in high-risk patient population [21]. Many studies have shown the non-inferiority of IV compared with IA TXA regarding both blood loss and thromboembolic complications. However, it is not clear whether the efficacy and safety of oral TXA administration is equal to or less than that of IA administration.

Some studies have demonstrated that tourniquet application may be related to tissue damage, severe thigh pain, and delayed rehabilitation [22]. In view of these concerns, no tourniquet was applied during the perioperative period at our institution. However, little is known about the efficacy and safety of oral TXA when tourniquet is not utilized in the knee surgery due to the substantial effect of tourniquet-related fibrinolysis on bleeding kinetics.

Thus, the objective of our prospective, randomized, double-blind trial, conducted in an enhanced recovery setup at our institution, was to assess the efficacy and safety of oral administration of three doses compared with IA administration of $3 \mathrm{~g}$ of TXA in the setting of primary unilateral TKA, with no tourniquet and drain. We hypothesized that oral TXA would be equivalent to IA TXA in reduction of blood loss and transfusion rates without increased thromboembolic complications.

\section{Methods}

This prospective, randomized, controlled trial was conducted at the Department of Joint Surgery in West China Hospital, Sichuan University. Approval was obtained from the Institutional Review Board (No. 201302008), and written informed consent and research authorizations were obtained from all participants. The trial was registered in the Chinese Clinical Trial Registry.

From March 2017 to July 2017, all patients (aged 18 year. or older) with primary osteoarthritis scheduled for undergoing primary unilateral TKA were screened for enrollment. All perioperative managements of TKA were conducted based on a well-established multimodal enhanced-recovery strategy, including pain control [23-25], blood-saving management [26], and early ambulation $[27,28]$. The exclusion criteria were secondary osteoarthritis (i.e., rheumatoid arthritis, post-septic arthritis, or post-traumatic arthritis), known allergy to TXA, a history of arterial or venous thromboembolic disease (i.e. deep venous thrombosis (DVT), or pulmonary embolism $(\mathrm{PE})$ ), a history of major comorbidities (i.e. severe pulmonary disease, severe renal insufficiency, hepatic failure, or severe stroke), a history of hematopoietic or hemophilia disease or active cancer, participation in another clinical trial during the last year, pregnancy, and alcohol abuse. These patients were also excluded if they declined to participate or refused to receive blood products.

\section{Drug delivery and randomization}

Recruited patients were randomly allocated to two interventions (i.e., oral-only or IA-only) based on a computergenerated randomization list, which was generated with use of Randomization.com.

\section{Group 1 (Oral TXA)}

Patients assigned to the oral group were given $2 \mathrm{~g}$ of TXA (4 tablets of $500 \mathrm{mg}$ ) by oral bolus appropriately $2 \mathrm{~h}$ before incision as a preoperative dose. A 
postoperative dose of $1 \mathrm{~g}$ was repeated 6 and $12 \mathrm{~h}$ after surgery, respectively. Also, the oral group received $100 \mathrm{~mL}$ of an intra-articular placebo solution ( $0.9 \%$ physiological saline solution) in a manner identical to the application of the solution in the IA group. Pharmacokinetic studies have demonstrated that $2 \mathrm{~g}$ oral TXA reaches therapeutic concentration after approximately 2 to $3 \mathrm{~h}$ and remains above the effective levels required to inhibit fibrinolysis for $6 \mathrm{~h}$ after such administration $[29,30]$.

\section{Group 2 (IA TXA)}

Patients assigned to the IA group received an intraarticular administration of $100 \mathrm{~mL}$ of saline solution containing a 3-g dose of TXA on the basis of previous study of topical TXA in TKA showing high efficacy for reducing bleeding with this dosage and concentration $[31,32]$. IA TXA (topical study medication) was administered at two points: (1) after all components were cemented and the joint was thoroughly irrigated, half of the volume (50 mL of 1.5-g TXA solution) was applied to soak the open joint surface and tissue for $5 \mathrm{~min}$; (2) the remaining half was administered using a needle to achieve tissue impregnation before capsule closure [32-34]. Moreover, the IA group was given small placebo pills identical to oral TXA in appearance and quantity with no active ingredient $2 \mathrm{~h}$ before incision, 6 and $12 \mathrm{~h}$ after surgery, respectively.

One experienced surgeon responsible for all TKAs enrolled all participants, and a research personnel prepared patient assignments, recorded practical details, and rechecked inclusion criteria. The randomization assignments were placed into sequentially numbered opaque sealed envelopes, which were kept by a certificated research pharmacist and were inaccessible through the investigation period. An envelope was opened on the day of surgery, and the appropriate study drug and placebo preparations were handled by a research pharmacist not involved in patient care to ensure identical appearance. The patients, trial participants, anesthesiologists, health-care providers, outcome assessors, and data collectors were blinded to allocation and route of TXA administration.

\section{Surgical procedure and postoperative management}

At our institution, the TKA was conducted by the same senior orthopaedic surgeons (XXX) under general anesthesia with a standard medial para-patellar approach. All prostheses were fixed with cement, and patella resurface technique was used in all patients.

All patients received multimodal analgesia consisting of adductor canal block $(20 \mathrm{ml} 5 \mathrm{~g} / \mathrm{L}$ ropivacaine and $0.1 \mathrm{mg}$ adrenaline) and periarticular multi-site infiltration $(70 \mathrm{ml} 2.5 \mathrm{~g} / \mathrm{L}$ ropivacaine and $0.1 \mathrm{mg}$ adrenaline) [35]. All patients also received a standard analgesia peri- operatively [23, 24]. Antibiotic prophylaxis in all patients was administered intravenously with $1.5 \mathrm{~g}$ of cefuroxime half an hour before surgery. No tourniquet, intraarticular drainage tube, and pressure dressing were applied in all patients in our center $[22,36]$.

\section{Thromboembolism prophylaxis protocol}

Patients received standard venous thromboembolism prophylaxis based on individualized protocol at our institution, including mechanical and chemical thromboprophylaxis. Patients were given mechanical prophylaxis by means of an intermittent inflatable lower-extremity pump on the first day after surgery, and lower-extremity strength training and passive and active physiotherapy were performed under the supervision of a professional physiotherapist. As for chemical prophylaxis, patients received low-molecular-weight heparin (LMWH; Clexane, Sanofi-Aventis, France, 2000 IU) administered subcutaneously appropriately $8 \mathrm{~h}$ after surgery and followed by 4000 IU once a day during hospitalization. Rivaroxaban (10 mg, Xarelto, Bayer, Germany) was administered orally once a day for 10 days after discharge if no bleeding events occurred.

\section{Blood transfusion protocol}

Participants were also received the standard practice of blood-transfusion protocol at our institution, which was consistent with the perioperative transfusion guidelines of Chinese Ministry of Health. Blood products were transfused if the hemoglobin $(\mathrm{Hb})$ level $<7 \mathrm{~g} / \mathrm{dL}$ in patients who were asymptomatic or if $\mathrm{Hb}$ level between 7 and $10 \mathrm{~g} / \mathrm{dL}$ in patients who developed concomitant clinical symptoms (anemia or myocardial ischemia) or if a patient with any anemia-related organ dysfunction regardless of $\mathrm{Hb}$ level.

\section{Outcome assessment}

The primary outcome was total blood loss. The estimated blood loss was calculated applying the Gross formula [37]:

Total blood loss $=\mathrm{PBV} \times\left(\mathrm{Hct}_{\text {pre }}-\mathrm{Hct}_{\text {post }}\right) / \mathrm{Hct}_{\text {ave }}$

$\mathrm{PBV}=$ patient $s$ blood volume

Hct $_{\text {pre }}=$ the initial preoperative hematocrit level

Hct $_{\text {post }}=$ the hematocrit level on the morning of the third postoperative day

$\mathrm{Hct}_{\text {ave }}=$ the average of the Hct $\mathrm{pre}_{\text {and }}$ Hct ${ }_{\text {post }}$

The PBV was assessed according to the formula of Nadler et al. [38]: PBV $(\mathrm{mL})=\mathrm{k}_{1} \mathrm{x}$ height $(\mathrm{m})+\mathrm{k}_{2} \mathrm{x}$ weight $(\mathrm{kg})+\mathrm{k}_{3} ; \mathrm{k}_{1}=0: 3669, \quad \mathrm{k}_{2}=0: 03219$, and $\mathrm{k}_{3}=$ $0: 6041$ for men; $k_{1}=0: 3561, k_{2}=0: 03308$, and $k_{3}=$ 
0:1833 for women. If a reinfusion or an allogenic transfusion was performed, the volume transfused should be added when calculating total blood loss.

The secondary outcomes included $\mathrm{Hb}$, reduction of $\mathrm{Hb}$ concentration, platelet concentration, hematocrit level, coagulation indicators (i.e., prothrombin time, INR, and activated partial thromboplastin time) on postoperative day (POD) 3, intraoperative blood loss, and amount of IV fluid. Other secondary outcomes included postoperative knee function (i.e., the range of motion and knee society score), pain score, quality of recovery (QoR-40), thromboembolic complications occurring $\leq 90$ days after surgery, surgical site infection, transfusion rates, and number of blood units transfused.

The active range of motion of the knee was measured with use of a standard clinical goniometer in a supine position before surgery and on postoperative 1 and 3 months. By the measurement of suction drains contents and surgical swabs, intraoperative blood loss was evaluated [39]. All patients were examined daily for clinical symptoms of DVT during hospitalization, including pain, swelling, tenderness, superficial venous engorgement, and Homan's sign in the thigh or calf. When a patient has any suspicious symptom of DVT, a diagnostic Doppler ultrasound was applied to exam both lower limbs by senior ultrasound physicians. All adverse events or thromboembolic events were noted during the first 3 months after surgery. All patients stayed in the hospital for a minimum of 3 days.

\section{Statistical analysis and sample size}

Statistical analyses were conducted using SPSS version 21.0 (SPSS Inc., Chicago, IL) software. A two-sided $P$ value of less than 0.05 was generally considered statistically significant for all comparisons. Distributions of demographic data, preoperative laboratory values, surgical data, knee function, and primary and secondary outcomes were assessed with summary statistics, including measures of central tendency (means and standard deviations) for quantitative data and numbers and percentages for qualitative data. Independent $\mathrm{t}$-test was used to compare the normal distributed continuous variables, and Wilcoxon Mann-Whitney U test was applied to analyze non-normal distribution or unequal variables. Pearson chi-square test or Fisher exact test was used for categorical variables. Before breaking the randomization code, statistical analyses were conducted blinded.

The sample-size estimate was determined based on the primary outcome (i.e., total blood loss). Sample size calculations were based on the preliminary data with a minimally clinically important difference of $10 \%$ and standard deviation of $15 \%$. Based on the abovementioned information, sample size estimation at an alpha (two-tailed) of 0.05 , power of $90 \%$, and standard effect size of 0.65 indicated that 62 patients were required for each arm. To compensate for the expected dropouts (20\%), 75 patients per group were planned to include in this study.

\section{Results}

\section{Patients}

During the recruitment period from March 2017 to July 2017, 238 patients scheduled for primary unilateral total knee arthroplasty were screened for participation in this trial. Eighty-eight patients were excluded for the following reasons: 71 were ineligible based on our exclusion criteria, 10 declined to participate, and 7 were excluded due to other reasons (Fig. 1). The remaining 150 patients underwent randomization to receive study medication. Three patients were excluded for various reasons, including tourniquet application (one patient), medication preparation not in time (one), and withdrew consent (one) (Fig. 1). Thus, a total of 147 eligible participants were randomized to receive oral TXA $(n=74)$ or IA TXA $(n=73)$ (Fig. 1). No patient was lost or excluded during follow-up.

No significant differences between the allocation groups were identified with respect to demographic data, perioperative surgical characteristics (i.e., operative time), preoperative Caprini score (i.e., evaluation of individual patients regarding DVT risk based on comorbidities and risk factors), knee function, and preoperative laboratory values (Table 1). The follow-up duration was 3 months after surgery.

\section{Blood loss}

The calculated blood loss (primary outcome) was 788.8 $\pm 349.1 \mathrm{~mL}$ in the oral group and $872.4 \pm 393.1 \mathrm{~mL}$ in the IA group $(p=0.21)$, respectively, with no significant difference between the groups. Regarding secondary outcomes, there were no differences among the groups in terms of intraoperative blood loss $(p=0.58)$ and the amount of postoperative IV fluids on POD $1(p=0.18)$ (Table 2).

\section{Postoperative laboratory values and clinical outcomes}

No difference between the two groups was identified regarding $\mathrm{Hb}$ level on POD 3 (Table 2). The reduction of $\mathrm{Hb}$ concentration on POD 3 were $2.2 \pm 0.9 \mathrm{~g} / \mathrm{dL}$ in oral group and $2.4 \pm 1.1 \mathrm{~g} / \mathrm{dL}$ in IA group, respectively, with no significant difference. Also, there were no significant differences identified regarding platelet count, hematocrit level, and red blood cell count on POD 3. In addition, blood coagulation values were similar between the groups (Table 2).

Moreover, knee range of motion and knee society score were similar among the groups at the three-month follow-up visit. Similarly, postoperative pain declined 


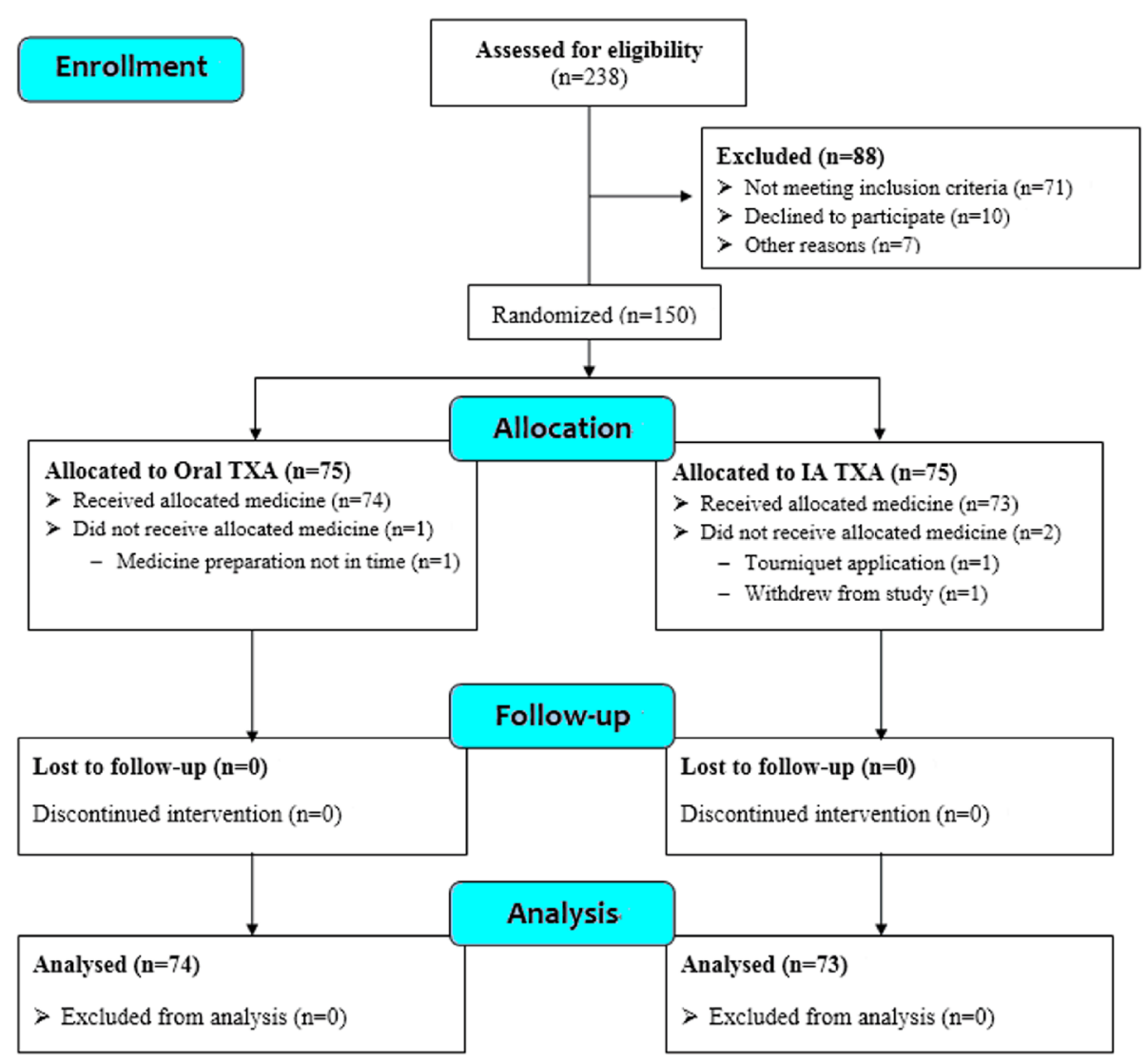

Fig. 1 CONSORT (Consolidated Standards of Reporting Trials) flow diagram

daily, and no significant difference was identified between groups at any follow-up point. When it comes to the severity of the knee swelling, there was no difference between the two groups at postoperative 3 months (Table 3). Moreover, there was no significant intergroup difference observed in terms of QoR-40 during the three-month follow-up visit (Table 3).

\section{Blood transfusion}

Seven patients received allogeneic blood transfusion due to a postoperative $\mathrm{Hb}$ of $<7 \mathrm{~g} / \mathrm{dL}$, including three patients $(4 \%)$ in the oral group and four $(5 \%)$ in the IA group, respectively, with no significant intergroup difference (Table 2). Similarly, there were no differences regarding the number of units of packed red blood cells transfused.

\section{Postoperative complications}

The frequency of DVT manifestations did not differ significantly between the groups, with 1 case in the oral group compared with none in the IA group. The diagnose of DVT was confirmed by Doppler ultrasonography. However, this patient showed no DVT-related clinical symptoms and was discharged and managed based on usual thromboembolism prophylaxis protocol at our center (Table 3) [32]. No superficial vein thrombosis and PE occurred in any group.

There was one adverse event in the oral group (one wound secretion) and one in the IA group (one hematoma), respectively. No superficial infection and gastric hemorrhage occurred in either group during follow-up period (Table 3). All adverse events were successfully resolved.

\section{Discussion}

Growing evidence has confirmed the efficacy of TXA in reducing blood loss and transfusion rates without additional complications [40, 41]. Our study was conducted to compare the effects of TXA regarding blood loss, transfusions and thromboembolic events, when administered by oral or IA modalities. Several studies have compared the efficacy of oral and IV use of TXA in TKA, while others have compared the effects of IA and IV administration of TXA. The present study was the first that we know of to evaluate two different routes of TXA administration in an enhanced-recovery setup without use of a tourniquet 
Table 1 Baseline characteristics and intraoperative demographics

\begin{tabular}{|c|c|c|c|}
\hline Variable & $\begin{array}{l}\text { Oral TXA Group } \\
(N=74)\end{array}$ & $\begin{array}{l}\text { IA TXA Group } \\
(N=73)\end{array}$ & $P$ value \\
\hline \multicolumn{4}{|l|}{ Patient characteristics } \\
\hline Age $(y r)^{b}$ & $65.0 \pm 13.1$ & $63.6 \pm 11.5$ & 0.51 \\
\hline Gender (Female/Male) $)^{a}$ & $58 / 16$ & $56 / 17$ & 0.81 \\
\hline Height $(m)^{b}$ & $1.5 \pm 0.1$ & $1.6 \pm 0.2$ & 0.39 \\
\hline Weight $(\mathrm{kg})^{\mathrm{b}}$ & $62.7 \pm 11.1$ & $62.9 \pm 9.5$ & 0.86 \\
\hline BMI $\left(\mathrm{kg} / \mathrm{m}^{2}\right)^{\mathrm{b}}$ & $25.1 \pm 4.1$ & $25.5 \pm 3.7$ & 0.52 \\
\hline Operated side $(L / R)^{a}$ & $47 / 27$ & $43 / 30$ & 0.57 \\
\hline \multicolumn{4}{|l|}{ ASA classification ${ }^{a}$} \\
\hline I & $15(20 \%)$ & $12(16 \%)$ & 0.79 \\
\hline$\|$ & 49 (66\%) & $52(71 \%)$ & \\
\hline III & $10(14 \%))$ & $9(10 \%)$ & \\
\hline IV & $0(0 \%)$ & $0(0 \%)$ & \\
\hline Caprini score $^{b}$ & $8.2 \pm 0.9$ & $8.4 \pm 1.1$ & 0.27 \\
\hline \multicolumn{4}{|l|}{ Preop. laboratory values ${ }^{\mathrm{b}}$} \\
\hline Hemoglobin (g/dL) & $13.4 \pm 1.3$ & $13.3 \pm 1.2$ & 0.40 \\
\hline Hematocrit (L/L) & $0.41 \pm 0.04$ & $0.41 \pm 0.03$ & 0.24 \\
\hline Platelet count $\left(\times 10^{9} / \mathrm{L}\right)$ & $186.4 \pm 53.6$ & $189.1 \pm 59.1$ & 0.77 \\
\hline $\begin{array}{l}\text { Red blood cell count }(\times \\
\left.10^{12} / L\right)\end{array}$ & $4.5 \pm 0.5$ & $4.5 \pm 0.4$ & 0.63 \\
\hline Prothrombin time (s) & $11.6 \pm 0.8$ & $11.7 \pm 0.9$ & 0.39 \\
\hline INR & $0.9 \pm 0.1$ & $1.0 \pm 0.2$ & 0.28 \\
\hline APTT (s) & $27.2 \pm 3.4$ & $28.2 \pm 3.6$ & 0.10 \\
\hline Fibrinogen ( $g / L)$ & $2.9 \pm 0.9$ & $2.7 \pm 0.8$ & 0.24 \\
\hline D-Dimer (mg/L) & $0.93 \pm 1.1$ & $1.0 \pm 1.3$ & 0.68 \\
\hline FDP (mg/L) & $2.7 \pm 2.1$ & $2.9 \pm 3.4$ & 0.62 \\
\hline \multicolumn{4}{|l|}{ Surgical data } \\
\hline Operative time $(\mathrm{min})^{\mathrm{b}}$ & $66.3 \pm 10.9$ & $68.8 \pm 12.8$ & 0.20 \\
\hline \multicolumn{4}{|l|}{ Preop. knee function ${ }^{b}$} \\
\hline QoR-40 & $150.9 \pm 4.5$ & $151.1 \pm 5.0$ & 0.89 \\
\hline $\mathrm{ROM}$ & $91.8 \pm 16.9$ & $92.1 \pm 16.7$ & 0.91 \\
\hline KSS & $45.4 \pm 10.3$ & $47.1 \pm 9.5$ & 0.29 \\
\hline Pain VAS score & $6.1 \pm 1.8$ & $6.2 \pm 1.9$ & 0.78 \\
\hline \multicolumn{4}{|l|}{ Knee circumference $(\mathrm{cm})^{\mathrm{b}}$} \\
\hline Upper pole of patella & $39.9 \pm 3.7$ & $39.7 \pm 5.5$ & 0.89 \\
\hline Lower pole of patella & $33.2 \pm 2.8$ & $32.7 \pm 3.1$ & 0.25 \\
\hline
\end{tabular}

ASA American Society of Anesthesiologists, PBV patient's blood volume, INR international normalized ratio, APTT activated partial thromboplastin time, FDP fibrinogen degradation product, $R O M$ range of motion, KSS knee society score, $B M I$ body mass index, VAS visual analogue scale, $Q O R-40$ quality of recovery-40 ${ }^{\text {a }}$ ata are presented as number of patients with percentage

${ }^{b}$ Data are presented as Mean \pm standard deviation

and postoperative drains in TKA. The major finding of this study was that oral administration of three doses of TXA was not inferior to IA administration of 3-g dose with respect to blood loss.
Table 2 Perioperative outcomes regarding blood loss

\begin{tabular}{|c|c|c|c|}
\hline Variable & $\begin{array}{l}\text { Oral TXA } \\
\text { Group }\end{array}$ & $\begin{array}{l}\text { IA TXA } \\
\text { Group }\end{array}$ & $P$ value \\
\hline \multicolumn{4}{|l|}{ Primary outcome } \\
\hline Total blood loss $(\mathrm{mL})^{\mathrm{b}}$ & $788.8 \pm 349.1$ & $872.4 \pm 393.1$ & 0.21 \\
\hline \multicolumn{4}{|l|}{ Secondary outcomes } \\
\hline $\begin{array}{l}\text { Intro-operative blood } \\
\text { loss }(\mathrm{mL})^{\mathrm{b}}\end{array}$ & $143.1 \pm 25.4$ & $145.6 \pm 28.7$ & 0.58 \\
\hline $\begin{array}{l}\text { Postop. IV fluid amount } \\
(\mathrm{mL})^{\mathrm{b}}\end{array}$ & $\begin{array}{l}2729.9 \pm \\
366.5\end{array}$ & $\begin{array}{l}2818.1 \pm \\
419.2\end{array}$ & 0.18 \\
\hline Blood transfusion $(U)^{a}$ & 7 & 9 & 0.73 \\
\hline Transfusion rate $(\%)^{a}$ & $3(4 \%)$ & $4(5 \%)$ & 0.69 \\
\hline \multicolumn{4}{|l|}{$\begin{array}{l}\text { Postop. laboratory values } \\
\text { at } 72 \mathrm{~h}^{\mathrm{b}}\end{array}$} \\
\hline Hemoglobin (g/dL) & $11.2 \pm 1.3$ & $10.9 \pm 1.2$ & 0.22 \\
\hline $\begin{array}{l}\text { Reduction of hemoglobin } \\
(\mathrm{g} / \mathrm{dL})\end{array}$ & $2.2 \pm 0.9$ & $2.4 \pm 1.1$ & 0.66 \\
\hline Hematocrit $(L / L)$ & $0.34 \pm 0.04$ & $0.32 \pm 0.03$ & 0.20 \\
\hline $\begin{array}{l}\text { Red blood cell count } \\
\left(\cdot \times 10^{12} / \mathrm{L}\right)\end{array}$ & $3.6 \pm 0.4$ & $3.5 \pm 0.4$ & 0.37 \\
\hline Platelet count $\left(\times 10^{9} / \mathrm{L}\right)$ & $165.8 \pm 53.2$ & $162.2 \pm 57.7$ & 0.70 \\
\hline Prothrombin time (s) & $11.7 \pm 1.3$ & $12.0 \pm 1.3$ & 0.17 \\
\hline INR & $0.9 \pm 0.1$ & $0.9 \pm 0.6$ & 0.76 \\
\hline APTT (s) & $30.8 \pm 5.0$ & $31.4 \pm 3.8$ & 0.38 \\
\hline Fibrinogen (g/L) & $4.5 \pm 1.0$ & $4.4 \pm 1.3$ & 0.67 \\
\hline D-Dimer (mg/L) & $3.4 \pm 2.2$ & $3.2 \pm 1.9$ & 0.60 \\
\hline $\mathrm{FDP}(\mathrm{mg} / \mathrm{L})$ & $9.2 \pm 6.4$ & $9.1 \pm 8.0$ & 0.96 \\
\hline
\end{tabular}

TXA tranexamic acid, INR international normalized ratio, APTT activated partial thromboplastin time, FDP fibrinogen degradation product

${ }^{a}$ Data are presented as number of patients with percentage

${ }^{\mathrm{b}}$ Data are presented as Mean \pm standard deviation

There are several limitations in our study. First, this trial had no placebo group, because the efficacy of TXA has been confirmed in many studies. In addition, the study patients receiving no TXA would be exposed to risks of no beneficial effects of TXA administration, such as reduction in blood loss and the need for transfusions, which may raise ethical issues. Second, we excluded patients undergoing bilateral or revision knee arthroplasty due to much larger blood loss compared with primary TKA; thus, our findings may not be suitable for these patients. Third, the duration of follow-up (3 months) may be short in this study; however, it was adequate to observe associated adverse reactions in three-month follow-up period, as the biological half-life of an intravenous TXA dose is 1.9 to $2.7 \mathrm{~h}, 90 \%$ of which was excreted within $24 \mathrm{~h}$. In addition, blood coagulation concentrations were also monitored for the risk of thrombogenesis postoperatively, which did not differ between groups. The finding was consistent with the previous study [42]. Fourth, no blood analyses were conducted to estimate serum tranexamic acid levels, and thus no 
Table 3 Postoperative outcomes regarding complications and knee function

\begin{tabular}{|c|c|c|c|}
\hline Variable & Oral TXA Group & IA TXA Group & $P$ value \\
\hline Postop. Complications (\%) & $2(2.7 \%)$ & $1(1.3 \%)$ & 0.76 \\
\hline DVT & 1 & 0 & 0.51 \\
\hline PE & 0 & 0 & - \\
\hline Superficial infection & 0 & 0 & - \\
\hline Hematoma & 0 & 1 & 0.50 \\
\hline Wound secretion & 1 & 0 & 0.51 \\
\hline Gastric hemorrhage & 0 & 0 & - \\
\hline \multicolumn{4}{|l|}{ Postop. knee function ${ }^{b}$} \\
\hline \multicolumn{4}{|l|}{ QoR-40 } \\
\hline $1 \mathrm{M}$ & $181.9 \pm 5.4$ & $183.4 \pm 6.6$ & 0.11 \\
\hline $3 \mathrm{M}$ & $189.4 \pm 5.9$ & $190.1 \pm 3.4$ & 0.34 \\
\hline \multicolumn{4}{|l|}{$\mathrm{ROM}^{\mathrm{b}}$} \\
\hline $1 \mathrm{M}$ & $113.9 \pm 8.7$ & $112.6 \pm 8.2$ & 0.37 \\
\hline $3 M$ & $122.4 \pm 10.4$ & $124.4 \pm 9.13$ & 0.17 \\
\hline \multicolumn{4}{|l|}{ Pain score ${ }^{b}$} \\
\hline POD 1 & $4.2 \pm 2.3$ & $4.5 \pm 1.5$ & 0.39 \\
\hline POD 3 & $2.4 \pm 1.4$ & $2.6 \pm 1.5$ & 0.37 \\
\hline $3 \mathrm{M}$ & $1.4 \pm 1.1$ & $1.3 \pm 1.2$ & 0.71 \\
\hline $\mathrm{KSS}^{\mathrm{b}}$ & $84.6 \pm 4.8$ & $85.9 \pm 7.1$ & 0.18 \\
\hline \multicolumn{4}{|l|}{ Knee circumference $(\mathrm{cm})^{\mathrm{b}}$} \\
\hline Upper pole of patella & $41.2 \pm 3.2$ & $41.8 \pm 6.0$ & 0.46 \\
\hline Lower pole of patella & $35.5 \pm 2.4$ & $36.0 \pm 3.2$ & 0.28 \\
\hline All cause 30 -day mortality ${ }^{a}$ & 0 & 0 & - \\
\hline All cause $90-$ day readmission ${ }^{a}$ & 0 & 0 & - \\
\hline
\end{tabular}

$R O M$ range of motion, QoR-40 quality of life-40, DVT deep vein thrombosis, $P E$ pulmonary embolism, KSS knee society score

${ }^{\mathrm{a} D a t a}$ are presented as number of patients with percentage

${ }^{\mathrm{b}}$ Data are presented as Mean \pm standard deviation

toxicity-related information can be provided after such TXA administration following TKA. Fifth, some confounding issues, such as complexity of surgical techniques and extent of soft tissue release, may have a substantial effect on the postoperative blood loss. However, these effects may be negligible due to the randomization design.

Tranexamic acid, an antifibrinolytic agent, can inhibit fibrinolysis though competitively inhibiting plasminogen activation and blocking the binding of plasminogen to fibrin and thereby prevent bleeding. At our institution, retrospective studies containing thousands of patients undergoing TKA revealed no increase in thromboembolic events rates [43]. TXA can be administered intravenously, intra-articularly, and orally. However, the majority of prior studies focused on IV or IA modalities of administration in TKA. However, concerns about the safety of IV and oral administration of TXA and the risk of thromboembolic events still remain for high-risk patient population, who has a history of a thromboembolic event, acute myocardial infarction, or ischemic cerebrovascular accident. In view of these safety concerns, topical application of TXA may be a safer route of administration to reduce postoperative bleeding without increasing the hypercoagulable state associated with knee surgery. IA use of TXA in surgical site can directly target the site of bleeding, achieve surgical hemostasis, and thereby inhibit local activation of fibrinolysis stimulated by surgical site. Also, high topical TXA dose can lead to greater thrombus formation and lower time to vascular occlusion, and result in enhanced microvascular hemostasis with low systemic absorption and less systemic side effects.

However, the dosage and concentration of TXA solution used in topical application show no clear-cut guidelines in studies. Existing data on clinical efficacy and safety of topical TXA administration compared with placebo in TKA have been confirmed in many RCTs with various dosages (1.5 to $3 \mathrm{~g}$ ) and topical routes of administration (Table 4). Some studies demonstrated that IA delivery of $>2$-g TXA can effectively reduce blood loss and transfusion requirements [44]. Moreover, a recent meta-analysis has confirmed that topical administration of $>2$-g TXA is a safe and simple alternative for patients with high risk of thromboembolic complications [45]. At our institution, a well-conducted RCT by Yue et al. has demonstrated that a high dose $(3 \mathrm{~g})$ of topical TXA appears to represent an effective and safe way to stop bleeding and transfusions [31]. Also, Huang et al. has demonstrated that a regimen with combined topical high-concentration TXA solution (1.5 g TXA diluted in $50 \mathrm{~mL}$ normal saline) and $1.5 \mathrm{~g}$ of IV TXA was effective in reducing the blood loss. This trial is a continuation of these previous studies, and compares efficacy of topical dose of $3 \mathrm{~g}$ of TXA with multiple doses of oral TXA administration.

Data on comparison of the effectiveness of oral TXA administration and placebo on blood loss, reduction of $\mathrm{Hb}$, and transfusions are summarized in Table 4 . Although oral application of TXA was effective in reducing blood loss, as also confirmed in a recent metaanalysis [46], to our knowledge, limited research has been conducted on the route of the less expensive oral form of TXA administration in TKA. A 4-armed RCT by Zohar included four treatment groups (i.e., IV TXA, oral TXA, IV plus oral TXA, and placebo) and demonstrated that oral application of TXA ( $1 \mathrm{~g}$ before surgery and repeat every $6 \mathrm{~h}$ for the next $18 \mathrm{~h}$ ) was superior to IV TXA administration due to significant difference in blood savings and ease of oral drug administration [15]. Fillingham et al. performed a RCT containing only 71 patients with the treatment groups of IV TXA and oral TXA. They found that a single gram of oral TXA $2 \mathrm{~h}$ 
Table 4 Overview of relevant randomized controlled trial regarding Oral and IA administration of TXA compared with placebo in total knee arthroplasty

\begin{tabular}{|c|c|c|c|c|c|c|c|c|}
\hline \multirow[t]{2}{*}{ Authors } & \multirow[t]{2}{*}{ Year } & \multirow[t]{2}{*}{ Dosing regimens } & \multicolumn{2}{|c|}{$\begin{array}{l}\text { No. of } \\
\text { patients }\end{array}$} & \multirow[t]{2}{*}{$\begin{array}{l}\text { Reduced } \\
\text { blood loss }\end{array}$} & \multirow[t]{2}{*}{$\begin{array}{l}\text { Reduction } \\
\text { of } \mathrm{Hb}\end{array}$} & \multirow[t]{2}{*}{$\begin{array}{l}\text { Increased } \\
\text { complications }\end{array}$} & \multirow[t]{2}{*}{$\begin{array}{l}\text { Reduced } \\
\text { transfusior }\end{array}$} \\
\hline & & & TXA & Control & & & & \\
\hline \multicolumn{9}{|l|}{ Oral administration } \\
\hline Zohar et al. & 2004 & $\begin{array}{l}1 \mathrm{~g} \text { oral TXA before surgery, } \\
6 \mathrm{~h}, 12 \mathrm{~h} \text {, and } 18 \mathrm{~h}\end{array}$ & 20 & 20 & Significant & NA & NS & Significant \\
\hline Charoencholvanich et al. & 2011 & $\begin{array}{l}10 \mathrm{mg} / \mathrm{kg} \text { before deflation; } \\
0.5 \mathrm{~g} \text { oral TXA for } 5 \text { days }\end{array}$ & 50 & 50 & Significant & Significant & NS & Significant \\
\hline Alipour et al. & 2013 & $\begin{array}{l}1 \mathrm{~g} \text { oral TXA before surgery, } \\
6 \mathrm{~h}, 12 \mathrm{~h} \text {, and } 18 \mathrm{~h}\end{array}$ & 26 & 27 & Significant & NA & NS & NA \\
\hline Lee et al. & 2017 & $\begin{array}{l}1 \mathrm{~g} \text { oral TXA } 2 \mathrm{~h} \text { before surgery, } \\
6 \text { and } 12 \mathrm{~h}\end{array}$ & 95 & 95 & Significant & Significant & NS & NA \\
\hline Yuan et al. & 2017 & $\begin{array}{l}20 \mathrm{mg} / \mathrm{kg} \text { oral TXA } 2 \mathrm{~h} \text { before } \\
\text { surgery; } 2 \mathrm{~g} \text { oral TXA } 12 \mathrm{~h} \\
\text { postoperatively }\end{array}$ & 140 & 140 & NA & Significant & NS & NA \\
\hline \multicolumn{9}{|l|}{ IA administration } \\
\hline Wong et al. (1) & 2010 & $1.5 \mathrm{~g} / 100 \mathrm{~mL}$ after cement & 33 & 35 & Significant & Significant & NS & NS \\
\hline Wong et al. (2) & 2010 & $3 \mathrm{~g} / 100 \mathrm{~mL}$ after cement & 31 & 35 & Significant & Significant & NS & NS \\
\hline Ishida et al. & 2011 & $2 \mathrm{~g} / 20 \mathrm{~mL}$ at closure & 50 & 50 & NA & NA & NS & NS \\
\hline $\begin{array}{l}\text { Sa-Ngasoongsong } \\
\text { et al. }\end{array}$ & 2011 & $0.25 \mathrm{~g} / 25 \mathrm{~mL}$ at closure & 24 & 24 & Significant & Significant & NS & Significant \\
\hline Onodera et al. & 2012 & $1 \mathrm{~g} / 50 \mathrm{~mL}$ after closure & 50 & 50 & Significant & Significant & NS & NS \\
\hline Roy et al. & 2012 & $0.5 \mathrm{~g} / 5 \mathrm{~mL}$ & 25 & 25 & NA & Significant & NS & NS \\
\hline Alshryda et al. & 2013 & $1 \mathrm{~g} / 50 \mathrm{~mL}$ at closure & 79 & 78 & Significant & Significant & NS & Significant \\
\hline Georgiadis et al. & 2013 & $2 \mathrm{~g} / 75 \mathrm{~mL}$ & 50 & 51 & Significant & Significant & NS & NS \\
\hline $\begin{array}{l}\text { Sa-Ngasoongsong } \\
\text { et al. (1) }\end{array}$ & 2013 & $0.25 \mathrm{~g} / 25 \mathrm{~mL}$ after closure & 45 & 45 & Significant & Significant & NS & NS \\
\hline $\begin{array}{l}\text { Sa-Ngasoongsong } \\
\text { et al. (2) }\end{array}$ & 2013 & $0.5 \mathrm{~g} / 25 \mathrm{~mL}$ after closure & 45 & 45 & Significant & Significant & NS & NS \\
\hline Martin et al. & 2014 & $2 \mathrm{~g} / 100 \mathrm{~mL}$ prior to closure & 25 & 25 & NA & Significant & NS & NA \\
\hline Lin et al. & 2015 & $1 \mathrm{~g} / 20 \mathrm{~mL}$ prior to closure & 40 & 40 & Significant & Significant & NS & Significant \\
\hline Wang et al. & 2015 & $0.5 \mathrm{~g} / 10 \mathrm{~mL}$ prior to closure & 30 & 30 & Significant & Significant & NS & Significant \\
\hline Yang et al. & 2015 & $0.5 \mathrm{~g} / 20 \mathrm{~mL}$ prior to closure & 40 & 40 & Significant & Significant & NS & Significant \\
\hline Maniar et al. & 2012 & $\begin{array}{l}3.0 \mathrm{~g} / 100 \mathrm{~mL} \text { before deflation } \\
\text { for } 5 \mathrm{mins}\end{array}$ & 40 & 40 & Significant & NA & NS & NS \\
\hline Seo et al. & 2013 & $1.5 \mathrm{~g} / 100 \mathrm{~mL}$ & 50 & 50 & Significant & NS & NS & Significant \\
\hline Sarzaeem et al. (1) & 2014 & $3.0 \mathrm{~g}$ TXA/100 mL before suturing & 50 & 50 & NA & NS & NS & NS \\
\hline Sarzaeem et al. (2) & 2014 & $1.5 \mathrm{~g}$ TXA/100 mL after closure & 50 & 50 & NA & Significant & NS & NS \\
\hline Aguilera et al. & 2015 & $1.0 \mathrm{~g} / 10 \mathrm{~mL}$ after cement & 50 & 50 & Significant & NS & NS & NS \\
\hline Cavusoglu et al. & 2015 & $2.0 \mathrm{~g} / 100 \mathrm{~mL}$ before closure & 20 & 20 & NA & NA & NS & NA \\
\hline Digas et al. & 2015 & $2.0 \mathrm{~g}$ TXA after closure & 30 & 30 & Significant & NS & NS & NS \\
\hline Oztas et al. & 2015 & $2.0 \mathrm{~g}$ TXA & 30 & 30 & Significant & NA & NS & Significant \\
\hline Drosos et al. & 2016 & $1.0 \mathrm{~g} / 30 \mathrm{~mL}$ & 30 & 30 & Significant & NS & NS & Significant \\
\hline Keyhani et al. & 2016 & $\begin{array}{l}1.5 \mathrm{~g} / 50 \mathrm{~mL} \text { before closure; } \\
1.5 \mathrm{~g} / 50 \mathrm{~mL} \text { after closure }\end{array}$ & 40 & 40 & Significant & Significant & NS & NS \\
\hline Tzatzairis et al. & 2016 & $1.0 \mathrm{~g} / 100 \mathrm{~mL}$ after closure & 40 & 40 & Significant & Significant & NS & Significant \\
\hline Prakash et al. (1) & 2017 & $3 \mathrm{~g} / 50 \mathrm{ml}$ prior to closure & 50 & 50 & NA & NA & NS & NS \\
\hline Prakash et al. (2) & 2017 & $3 \mathrm{~g} / 50 \mathrm{ml}$ after closure & 50 & 50 & NA & NA & NS & NS \\
\hline Song et al. & 2017 & $3 \mathrm{~g} / 50 \mathrm{ml}$ after closure & 50 & 50 & Significant & Significant & NS & NS \\
\hline
\end{tabular}


Table 4 Overview of relevant randomized controlled trial regarding Oral and IA administration of TXA compared with placebo in total knee arthroplasty (Continued)

\begin{tabular}{|c|c|c|c|c|c|c|c|c|}
\hline \multirow[t]{2}{*}{ Authors } & \multirow[t]{2}{*}{ Year } & \multirow[t]{2}{*}{ Dosing regimens } & \multicolumn{2}{|c|}{$\begin{array}{l}\text { No. of } \\
\text { patients }\end{array}$} & \multirow[t]{2}{*}{$\begin{array}{l}\text { Reduced } \\
\text { blood loss }\end{array}$} & \multirow[t]{2}{*}{$\begin{array}{l}\text { Reduction } \\
\text { of } \mathrm{Hb}\end{array}$} & \multirow[t]{2}{*}{$\begin{array}{l}\text { Increased } \\
\text { complications }\end{array}$} & \multirow[t]{2}{*}{$\begin{array}{l}\text { Reduced } \\
\text { transfusion }\end{array}$} \\
\hline & & & TXA & Control & & & & \\
\hline Stowers et al. & 2017 & $1.5 \mathrm{~g} \mathrm{TXA}$ & 59 & 21 & Significant & NA & NS & NS \\
\hline Ugurlu et al. & 2017 & $\begin{array}{l}1.5 \mathrm{~g} / 50 \mathrm{~mL} \text { before closure; } \\
1.5 \mathrm{~g} / 50 \mathrm{~mL} \text { after closure }\end{array}$ & 42 & 41 & NA & Significant & NS & NS \\
\hline Yuan et al. & 2017 & $3 \mathrm{~g} / 60 \mathrm{ml}$ after closure & 140 & 140 & NA & Significant & NS & Significant \\
\hline
\end{tabular}

NA not available, NS not significant

before incision can provide an equivalent reduction in $\mathrm{Hb}$ level and blood loss in comparison with IV medicine administration [47]. In spite of the blood-sparing efficacy and potential cost-saving benefits of oral TXA, some concerns do remain about thromboembolic complications after oral administration in high-risk patient population. In addition, a tourniquet and postoperative drain were applied as a standard practice in the abovementioned studies. Thus, it remains unclear whether the efficacy and safety of oral TXA is equal to or less than that of IA TXA in TKA without a tourniquet and drain.

Some drainage-related factors, such as the gradually declining hematocrit in drain output and residual blood in the drain, could have an effect on the accuracy of blood loss measurement [48]. A RCT conducted by Wang et al. [36] demonstrated that the postoperative drainage provided no clear benefits in blood loss, knee function, and early recovery in primary TKA. Moreover, Huang et al. performed a RCT of application of tourniquet in TKA at our institution and reported that tourniquet application may cause muscle damage and delay strength recovery [22]. Also, a recent meta-analysis has confirmed that tourniquet could increase the risk of thromboembolic events [49]. Some RCTs have demonstrated that the lack of tourniquet did not affect the tibial cement mantle thickness [50] and short-term fixation [51]. Thus, the tourniquet and postoperative drain were not applied after surgery routinely. The tourniquetrelated fibrinolysis may have a substantial effect on bleeding kinetics, which is related to the assessment of the effect of oral TXA administration when a tourniquet is not utilized in the procedure.

Although our trial had a similar goal of comparing oral and other routes of TXA administration as the abovementioned studies, we assessed the efficacy of perioperative standardized oral TXA versus IA TXA alone for unilateral TKA, conducted in a fast-track setup, without the use of a tourniquet and postoperative drains. The dosing and timing of oral regimes were based on pharmacokinetic and serum studies, and therapeutic levels can be maintained for approximately $12 \mathrm{~h}$ after surgery, which covers the most period of postoperative hyperfibrinolysis. The major finding of our study was that oral TXA administration provided an equivalent blood-saving benefit when compared with IA administration of $3 \mathrm{~g}$ of TXA.

Blood-conservation strategy during "enhanced recovery" knee replacement, as part of multimodal protocol, has substantially affected costs by decreasing the incidence of morbidity and mortality, transfusion-associated complications, and hospital stay. The finding was supported by a retrospective economic analysis of TXA application, which indicated $\$ 879$ direct savings per joint surgery with use of TXA [52]. Moreover, a retrospective analysis by Irwin et al. [29] contained 2698 patients undergoing total joint arthroplasty and demonstrated that the patients receiving the substituted 2-g oral TXA bolus had a lower risk of blood transfusion, with great cumulative savings $(£ 29,788)$, when in comparison with $15-\mathrm{mg} / \mathrm{kg}$ IV administration. Retrospective clinical and cost-benefit evaluation of IA TXA administration have shown an estimated cost savings of $\$ 1500$ per patient with decreased transfusion costs [53]. A RCT by Kayupov et al. reported that an appropriate oral dose can save $\$ 33$ to $\$ 94$ compared with an equivalent dose depending on the TXA formulation and administration route selected [20]. In China, more than 200,000 primary TKAs were conducted annually. Considering aging population and longer life expectancy, the number of TKAs will increase dramatically over time [54]. Thus, a transition to oral TXA may lead to great cost savings per year for health-care system.

No significant differences identified in transfusion rates and thromboembolic complications (i.e., DVT and $\mathrm{PE})$ in this current study. However, there is substantial evidence supporting the safety of oral and IA application of TXA with no additional thromboembolic complications. In our study, there was no significant differences between the two groups regarding knee function and quality of life, which were tested with use of range of motion, knee society score, pain score, and QoR-40 measures after surgery.

\section{Conclusions}

This prospective randomized controlled trial in the setting of total knee arthroplasty using a fast-track protocol, with no tourniquet and postoperative drain, 
demonstrated that oral administration of TXA (2-g TXA before incision and $1 \mathrm{~g}$ TXA every $6 \mathrm{~h}$ for $12 \mathrm{~h}$ after surgery) provided an equivalent blood-saving benefit compared with $3 \mathrm{~g}$ of IA TXA administration with great cost savings and no increased thromboembolic events.

\section{Abbreviations}

IA: Intra-articular; IV: Intravenous; RCT: Randomized controlled trials; TKA: Total knee arthroplasty; TXA: Tranexamic acid

\section{Acknowledgements}

We would like to thank the relevant staff for guidance and assistance for their support and collaboration in our hospital.

\section{Funding}

No funding was obtained for this study.

\section{Availability of data and materials}

The datasets used and/or analyzed during the current study are available from the corresponding author on reasonable request.

\section{Authors' contributions}

ZKZ, FXP, and QL conceived and designed this study; DW, HZ, WKM, and HYW collected the data; DW, HYW, DW, and ZYL performed the statistical analysis; HYW and DW prepared tables 1-4; DW, HYW, and ZYL prepared figure 1; DW, WKM, and HYW wrote the manuscript; DW, QL, HZ, and ZKZ revised this manuscript. All authors reviewed the final manuscript. All authors agree to be accountable for all aspects of the work.

\section{Ethics approval and consent to participate}

This study was approved by the local institutional review board of West China Hospital, Sichuan University (No. 201302008). Written informed consent (including patients' details, images or videos) was obtained from all participants. The trial was registered in the Chinese Clinical Trial Registry (ChiCTR-INR-17010968) dated 23rd March 2017. All experiments were performed in accordance with relevant guidelines and regulations. This study was conducted in accordance to the Declaration of Helsinki.

\section{Consent for publication}

Not applicable.

\section{Competing interests}

The authors declare that they have no competing interests.

\section{Publisher's Note}

Springer Nature remains neutral with regard to jurisdictional claims in published maps and institutional affiliations.

\section{Author details \\ 'Department of Orthopedics, West China Hospital/West China School of Medicine, Sichuan University, 37\# Wuhou Guoxue road, Chengdu 610041 People's Republic of China. ${ }^{2}$ Out-patient department, West China Second University Hospital, Sichuan University, Chengdu 610041, People's Republic of China. ${ }^{3}$ Key Laboratory of Birth Defects and Related Disease of Woman and Children (Ministry of Education), West China Second University Hospital, Sichuan University, Chengdu 610041, People's Republic of China.}

Received: 4 November 2017 Accepted: 28 February 2018 Published online: 15 March 2018

\section{References}

1. Bierbaum BE, Callaghan JJ, Galante JO, Rubash HE, Tooms RE, Welch RB. An analysis of blood management in patients having a total hip or knee arthroplasty. J Bone Joint Surg Am. 1999;81(1):2-10.

2. Bong MR, Patel V, Chang E, Issack PS, Hebert R, Di Cesare PE. Risks associated with blood transfusion after total knee arthroplasty. J Arthroplast. 2004;19(3):281-7.
3. Freedman J, Luke K, Monga N, Lincoln S, Koen R, Escobar M, et al. A provincial program of blood conservation: the Ontario Transfusion Coordinators (ONTraC). Transfus Apher Sci. 2005;33(3):343-9.

4. Good L, Peterson E, Lisander B. Tranexamic acid decreases external blood loss but not hidden blood loss in total knee replacement. Br J Anaesth. 2003:90(5):596-9.

5. Blajchman MA, Beckers EA, Dickmeiss E, Lin L, Moore G, Muylle L. Bacterial detection of platelets: current problems and possible resolutions. Transfus Med Rev. 2005;19(4):259-72.

6. Fuller AK, Uglik KM, Savage WJ, Ness PM, King KE. Bacterial culture reduces but does not eliminate the risk of septic transfusion reactions to singledonor platelets. Transfusion. 2009;49(12):2588-93.

7. Kirksey M, Chiu YL, Ma Y, Della Valle AG, Poultsides L, Gerner P, et al. Trends in in-hospital major morbidity and mortality after total joint arthroplasty: United States 1998-2008. Anesth Analg. 2012;115(2):321-7.

8. Leigheb M, Pogliacomi F, Bosetti M, Boccafoschi F, Sabbatini M, Cannas M, et al. Postoperative blood salvage versus allogeneic blood transfusion in total knee and hip arthroplasty: a literature review. Acta Biomed. 2016;87(Suppl 1):6-14.

9. Markert SE. The use of cryotherapy after a total knee replacement: a literature review. Orthop Nurs. 2011;30(1):29-36.

10. Sharrock NE, Salvati EA. Hypotensive epidural anesthesia for total hip arthroplasty: a review. Acta Orthop Scand. 1996;67(1):91-107.

11. Themistoklis T, Theodosia V, Konstantinos K, Georgios DI. Perioperative blood management strategies for patients undergoing total knee replacement: where do we stand now? World J Orthop. 2017;8(6):441-54.

12. Astedt B. Clinical pharmacology of tranexamic acid. Scand J Gastroenterol Suppl. 1987;137:22-5.

13. Okamoto S, Hijikata-Okunomiya A, Wanaka K, Okada Y, Okamoto U. Enzyme-controlling medicines: introduction. Semin Thromb Hemost. 1997;23(6):493-501.

14. Alipour M, Tabari M, Keramati M, Zarmehri AM, Makhmalbaf H. Effectiveness of oral tranexamic acid administration on blood loss after knee artroplasty: a randomized clinical trial. Transfus Apher Sci. 2013;49(3):574-7.

15. Zohar E, Ellis M, Ifrach N, Stern A, Sapir O, Fredman B. The postoperative blood-sparing efficacy of oral versus intravenous tranexamic acid after total knee replacement. Anesth Analg. 2004:99(6):1679-83. table of contents

16. Goyal N, Chen DB, Harris IA, Rowden NJ, Kirsh G, MacDessi SJ. Intravenous vs intra-articular tranexamic acid in total knee arthroplasty: a randomized, double-blind trial. J Arthroplast. 2017;32(1):28-32.

17. Tzatzairis TK, Drosos Gl, Kotsios SE, Ververidis AN, Vogiatzaki TD, Kazakos KI. Intravenous vs topical tranexamic acid in total knee arthroplasty without tourniquet application: a randomized controlled study. J Arthroplast. 2016; 31(11):2465-70.

18. Sun X, Dong Q, Zhang YG. Intravenous versus topical tranexamic acid in primary total hip replacement: a systemic review and meta-analysis. Int J Surg. 2016;32:10

19. Luo ZY, Wang HY, Wang D, Zhou K, Pei FX, Zhou ZK. Oral vs intravenous vs topical tranexamic acid in primary hip arthroplasty: a prospective, randomized, double-blind, controlled study. J Arthroplast. 2018:33(3):786-93.

20. Kayupov E, Fillingham YA, Okroj K, Plummer DR, Moric M, Gerlinger TL, et al. Oral and intravenous tranexamic acid are equivalent at reducing blood loss following total hip arthroplasty: a randomized controlled trial. J Bone Joint Surg Am. 2017:99(5):373-8

21. Wong J, Abrishami A, El Beheiry H, Mahomed NN, Roderick Davey J, Gandhi $R$, et al. Topical application of tranexamic acid reduces postoperative blood loss in total knee arthroplasty: a randomized, controlled trial. J Bone Joint Surg Am. 2010;92(15):2503-13.

22. Huang ZY, Pei FX, Ma J, Yang J, Zhou ZK, Kang PD, et al. Comparison of three different tourniquet application strategies for minimally invasive total knee arthroplasty: a prospective non-randomized clinical trial. Arch Orthop Trauma Surg. 2014;134(4):561-70

23. Lei YT, Xu B, Xie XW, Xie JW, Huang Q, Pei FX. The efficacy and safety of two low-dose peri-operative dexamethasone on pain and recovery following total hip arthroplasty: a randomized controlled trial. Int Orthop. 2017:42(3):499-505.

24. Li D, Yang Z, Xie X, Zhao J, Kang P. Adductor canal block provides better performance after total knee arthroplasty compared with femoral nerve block: a systematic review and meta-analysis. Int Orthop. 2015;40(5):925-33.

25. Xu B, Ma J, Huang Q, Huang ZY, Zhang SY, Pei FX. Two doses of low-dose perioperative dexamethasone improve the clinical outcome after total knee arthroplasty: a randomized controlled study. Knee Surg Sports Traumatol Arthrosc. 2017;472(1):169-74. 
26. Ma J, Huang Z, Shen B, Pei F. Blood management of staged bilateral total knee arthroplasty in a single hospitalization period. J Orthop Surg Res. 2014;9:116.

27. Wang D, Yang Y, Li Q, Tang SL, Zeng WN, Xu J, et al. Adductor canal block versus femoral nerve block for total knee arthroplasty: a meta-analysis of randomized controlled trials. Sci Rep. 2017;7:40721.

28. Zeng WN, Zhou K, Zhou ZK, Shen B, Yang J, Kang PD, et al. Comparison between drainage and non-drainage after total hip arthroplasty in Chinese subjects. Orthop Surg. 2014;6(1):28-32.

29. Irwin A, Khan SK, Jameson SS, Tate RC, Copeland C, Reed MR. Oral versus intravenous tranexamic acid in enhanced-recovery primary total hip and knee replacement: results of 3000 procedures. Bone Joint J. 2013;95-b(11):1556-61.

30. Pilbrant A, Schannong M, Vessman J. Pharmacokinetics and bioavailability of tranexamic acid. Eur J Clin Pharmacol. 1981;20(1):65-72.

31. Yue C, Kang P, Yang P, Xie J, Pei F. Topical application of tranexamic acid in primary total hip arthroplasty: a randomized double-blind controlled trial. J Arthroplast. 2014;29(12):2452-6.

32. Huang Z, Ma J, Shen B, Pei F. Combination of intravenous and topical application of tranexamic acid in primary total knee arthroplasty: a prospective randomized controlled trial. J Arthroplast. 2014;29(12):2342-6.

33. Gomez-Barrena E, Ortega-Andreu M, Padilla-Eguiluz NG, Perez-Chrzanowska $\mathrm{H}$, Figueredo-Zalve R. Topical intra-articular compared with intravenous tranexamic acid to reduce blood loss in primary total knee replacement: a double-blind, randomized, controlled, noninferiority clinical trial. J Bone Joint Surg Am. 2014;96(23):1937-44.

34. Nielsen CS, Jans O, Orsnes T, Foss NB, Troelsen A, Husted H. Combined intra-articular and intravenous tranexamic acid reduces blood loss in total knee arthroplasty: a randomized, double-blind, placebo-controlled trial. J Bone Joint Surg Am. 2016;98(10):835-41.

35. Li D, Tan Z, Kang P, Shen B, Pei F. Effects of multi-site infiltration analgesia on pain management and early rehabilitation compared with femoral nerve or adductor canal block for patients undergoing total knee arthroplasty: a prospective randomized controlled trial. Int Orthop. 2017:41(1):75-83.

36. Wang D, Xu J, Zeng WN, Zhou K, Xie TH, Chen Z, et al. Closed suction drainage is not associated with faster recovery after total knee arthroplasty: a prospective randomized controlled study of 80 patients. Orthop Surg. 2016:8(2):226-33.

37. Gross JB. Estimating allowable blood loss: corrected for dilution. Anesthesiology. 1983;58(3):277-80.

38. Nadler SB, Hidalgo JH, Bloch T. Prediction of blood volume in normal human adults. Surgery. 1962:51(2):224-32.

39. Zhou K, Wang H, Li J, Wang D, Zhou Z, Pei F. Non-drainage versus drainage in tourniquet-free knee arthroplasty: a prospective trial. ANZ J Surg. 2017:87:1048.

40. Wang CG, Sun ZH, Liu J, Cao JG, Li ZJ. Safety and efficacy of intra-articular tranexamic acid injection without drainage on blood loss in total knee arthroplasty: a randomized clinical trial. Int J Surg. 2015;20:1-7.

41. Yang Y, LV YM, Ding PJ, Li J, Ying-Ze Z. The reduction in blood loss with intra-articular injection of tranexamic acid in unilateral total knee arthroplasty without operative drains: a randomized controlled trial. Eur J Orthop Surg Traumatol. 2015;25(1):135-9.

42. Jansen AJ, Andreica S, Claeys M, D'Haese J, Camu F, Jochmans K. Use of tranexamic acid for an effective blood conservation strategy after total knee arthroplasty. Br J Anaesth. 1999;83(4):596-601.

43. Xie J, Ma J, Kang P, Zhou Z, Shen B, Yang J, et al. Does tranexamic acid alter the risk of thromboembolism following primary total knee arthroplasty with sequential earlier anticoagulation? A large, single center, prospective cohort study of consecutive cases. Thromb Res. 2015;136(2):234-8.

44. Prakash J, Seon JK, Park YJ, Jin C, Song EK. A randomized control trial to evaluate the effectiveness of intravenous, intra-articular and topical wash regimes of tranexamic acid in primary total knee arthroplasty. J Orthop Surg (Hong Kong). 2017;25(1):2309499017693529.

45. Shin YS, Yoon JR, Lee HN, Park SH, Lee DH. Intravenous versus topical tranexamic acid administration in primary total knee arthroplasty: a metaanalysis. Knee Surg Sports Traumatol Arthrosc. 2016;25(11):3585-595.

46. Zhang LK, Ma JX, Kuang MJ, Zhao J, Wang Y, Lu B, et al. Comparison of oral versus intravenous application of tranexamic acid in total knee and hip arthroplasty: a systematic review and meta-analysis. Int J Surg. 2017:45:77-84.

47. Fillingham YA, Kayupov E, Plummer DR, Moric M, Gerlinger TL, Della Valle CJ. The James A. Rand Young Investigator's Award: a randomized controlled trial of oral and intravenous tranexamic acid in total knee arthroplasty: the same efficacy at lower cost? J Arthroplast. 2016;31(9 Suppl):26-30.
48. Quinn M, Bowe A, Galvin R, Dawson P, O'Byrne J. The use of postoperative suction drainage in total knee arthroplasty: a systematic review. Int Orthop. 2015;39(4):653-8.

49. Zhang W, Li N, Chen S, Tan Y, Al-Aidaros M, Chen L. The effects of a tourniquet used in total knee arthroplasty: a meta-analysis. J Orthop Surg Res. 2014;9(1):13.

50. Pfitzner T, von Roth P, Voerkelius N, Mayr H, Perka C, Hube R. Influence of the tourniquet on tibial cement mantle thickness in primary total knee arthroplasty. Knee Surg Sports Traumatol Arthrosc. 2014;24(1):96-101.

51. Ledin H, Aspenberg P, Good L. Tourniquet use in total knee replacement does not improve fixation, but appears to reduce final range of motion: a randomized RSA study involving 50 patients. Acta Orthop. 2012;83(5):499-503.

52. Gillette BP, Maradit Kremers H, Duncan CM, Smith HM, Trousdale RT, Pagnano MW, et al. Economic impact of tranexamic acid in healthy patients undergoing primary total hip and knee arthroplasty. J Arthroplast. 2013:28(8 Suppl):137-9.

53. Chimento GF, Huff T, Ochsner JL Jr, Meyer M, Brandner L, Babin S. An evaluation of the use of topical tranexamic acid in total knee arthroplasty. Arthroplast. 2013;28(8 Suppl):74-7.

54. Dai K-R, Li H-W, Yan M-N. Twenty-year accelerated development of artificial joints in China. Chin J Joint Surg. 2015;9(6):691-4.

\section{Submit your next manuscript to BioMed Central and we will help you at every step:}

- We accept pre-submission inquiries

- Our selector tool helps you to find the most relevant journal

- We provide round the clock customer support

- Convenient online submission

- Thorough peer review

- Inclusion in PubMed and all major indexing services

- Maximum visibility for your research

Submit your manuscript at www.biomedcentral.com/submit
) Biomed Central 